\title{
The outcome of the sofosbuvir Based Therapy in the treatment of Hepatitis C Virus Genotype 4 in Egyptian patients
}

\author{
Waleed Abdul Fattah Ismail', Amr Shaaban Hanafy ${ }^{1}$, Mohammed Abdelsattar ${ }^{2}$ \\ 1: Assistant professor of internal medicine, gastroenterology and hepatology unit, faculty of medicine, Zagazig University. \\ 2: Internal Medicine Department- Mansura University. \\ DOI: https://dx.doi.org/10.52378/alkj/2738 \\ Corresponding author: Amr Shaaban Hanafy, \\ Assistant professor of internal medicine, gastroenterology and hepatology unit, faculty of medicine, Zagazig University. \\ Dramr hanafy@yahoo.com
}

Sharkia, Zagazig, 44519

40- Mostafa Fouad St.,

Cellphone:

$+201100061861$

Received: November 3, 2018

Peer-review started: November 5, 2018

First decision: November 12, 2018

Revised: November 27, 2018

The second round of peer review (by journal editors): January 29, 2019

Accepted: February 1, 2019

Article in press: February 2, 2019

First online: February 5, 2019.

Informed consent statement: Informed consent was obtained from the patient.

Conflict-of-interest statement: All authors declare no conflict-of-interest related to this article.

\section{Funding Sources}

The research is self-funded. 


\section{Abstract}

\section{Background and aim}

There have been significant advancements during the last few years, with large numbers of ongoing trials with various direct-acting antivirals (DAA) showing high potency against the hepatitis $\mathrm{C}$ virus (HCV). The aim was to show the effectiveness and side effects of Sofosbuvirbased therapy in treating HCV genotype 4 in Egyptian patients and compare its results with the international results.

\section{Methods}

The study included 740 patients with chronic HCV. The study population consisted of three groups: Group (1): included 240 patients treated with sofosbuvir $400 \mathrm{mg}$ plus Peginterferon $\alpha 2 \mathrm{a}$ and weight-based ribavirin for 12 weeks. Group (2): had 250 patients treated with sofosbuvir $400 \mathrm{mg}$ and weight-based ribavirin for 24 weeks. Group (3): involved 250 patients treated with sofosbuvir $400 \mathrm{mg}$ and simeprevir $150 \mathrm{mg}$ once daily for 12 weeks.

\section{Results}

Sustained virological response (SVR) occurred in $83.3 \%$ of the triple therapy group. In the dual therapy group, SVR occurred in $64 \%$ of patients. In the Simeprevir-Sofosbuvir group, SVR was achieved in $96 \%$ of patients, with statistically significant differences among the studied groups $(p=0.015)$. Multivariate logistic regression analysis showed that treatment with simeprevir and sofosbuvir was associated with higher rates of SVR with an odds ratio of 12.5. Serum creatinine shows a negative correlation with an odds ratio of 3.1; MELD score showed a negative correlation with an odds ratio of 1.5 .

\section{Conclusion}

Sofosbuvir-based therapy has satisfactory results for the treatment of hepatitis $C$ virus genotype 4 with lesser complications

\section{Keywords}

Outcome; sofosbuvir Based Therapy; Hepatitis C Virus; genotype 4; Egyptians 


\section{Introduction}

The prevalence of HCV antibody was $10.0 \%$, and that of HCV RNA by $7.0 \%$ (95\% CI 6.6-7.4). In children 1-14 years old, HCV antibody and HCV RNA prevalence were $0.4 \%$ and $0.2 \%$, respectively (1). The cause of this high incidence is not well understood. Still, the mass parenteral therapy for schistosomiasis could explain it in the second half of the 20th century, which was the determinant factor of the high prevalence.

Almost all patients with chronic HCV were caused by genotype 4, representing over 90\% of cases in Egypt. Cirrhosis and hepatocellular carcinoma in Egypt are attributed mainly to chronic active $\mathrm{HCV}$.

Chronic $\mathrm{HCV}$ is a slowly progressive disease characterized by persistent hepatic inflammation with persistent viremia for more than six months. It will eventually lead to liver cirrhosis in approximately $10-20 \%$ of patients over $20-30$ years of $\mathrm{HCV}$ infection (2).

Cirrhosis may be indolent for many years in some patients and may progress in others to hepatocellular carcinoma, hepatic decompensation, and death. After cirrhosis has developed, there is a $1-5 \%$ annual risk of $\mathrm{HCC}$ and a $3-6 \%$ yearly risk of hepatic decompensation. After liver decompensation, the risk of death in the following year is between $15 \%$ and $20 \%$ (3).

The treatment of HCV infection with pegylated interferon-alpha and ribavirin had led to sustained virologic response (SVR) in around 55-60\% with HCV genotype 4 (4). Treatment aims to eradicate HCV RNA, which is predicted by the achievement of SVR defined by the absence of HCV RNA by polymerase chain reaction (PCR) six months after stopping treatment (5).

In Egypt, the initial therapeutic wave of effective management of Chronic HCV included Peginterferon alfa and ribavirin. The optimal dose of peginterferon alfa-2a is a fixed dose of $180 \mu \mathrm{g} /$ week given subcutaneously together with ribavirin; 1,000 $\mathrm{mg}$ for those who weigh $\leq 75 \mathrm{~kg}$ and $1,200 \mathrm{mg}$ for those who weigh $>75 \mathrm{~kg}(6)$. 
Interferon mediates its antiviral effect by inducing interferon-stimulated genes (ISGs), which encode for a number of some effector proteins with antiviral effects such as protein kinase (PKR), 2', 5' oligoadenylate synthetase, and adenosine deaminase leading to inhibition of mRNA translation, RNA degradation, editing and production of nitric oxide (7).

Ribavirin is a guanosine analog that produces broad-spectrum antiviral activities (8). Ribavirin's antiviral ability results from four pathways; direct inhibition of HCV replication, inhibition of host inosine monophosphate dehydrogenase (IMPDH) enzyme, mutagenesis induction to drive a rapidly replicating virus beyond the threshold to error catastrophe, and immunomodulation by inducing a Th1 immune response(9).

Direct-acting antivirals work to inhibit the three viral proteins NS3/4A protease, the NS5A protein, and the NS5B RNA-dependent RNA polymerase; they reduce the length of antiviral treatment, improve response rates, and allow for interferon-free regimens (10).

Since the HCV NS5B polymerase's active site is highly conserved across genotypes, nucleos $(\mathrm{t})$ ide inhibitors tend to have a pan-genotypic activity. Many also have a high genetic barrier to drug resistance. In contrast, non-nucleoside polymerase inhibitors bind distal to the catalytic site, are less likely to have pan-genotypic activity, and have a lower genetic barrier to resistance (11).

Sofosbuvir is a direct-acting pyrimidine nucleoside analog representing the first NS5B $\mathrm{HCV}$ polymerase inhibitor. It undergoes intracellular metabolism to form the pharmacologically active uridine analog triphosphate, which can be incorporated into HCV RNA by the NS5B RNA-dependent RNA polymerase (RdRp) acting as a chain terminator. It is active against all HCV genotypes(12). It has a high resistance barrier. No S282T mutation was detected in patients who relapsed after receiving sofosbuvir combined with RBV with or without peg-IFN or a second DAA (13).

Simeprevir is an oral $\mathrm{HCV} \mathrm{NS3/4A} \mathrm{protease} \mathrm{inhibitor} \mathrm{approved} \mathrm{to} \mathrm{treat} \mathrm{HCV}$ and compensated liver disease patients. It is classified as a 
Second-generation protease inhibitor with a macrocyclic structure, presenting an advantage regarding binding affinity and specificity for NS3 protease compared to first-generation protease inhibitors (14).

This work evaluates the effectiveness and side effects of initial Sofosbuvir-based therapies in treating Hepatitis Genotype 4 in Egyptian patients. Also, to compare our results with pegylated interferon included treatment, which is now considered obsolete from the Egyptian national guidelines.

\section{Methods}

This retrospectivewasnter study was conducted in the hepatology Outpatient clinic Zagazig university hospital, AL-Ahrar hospital virology center, and Fakous virology center from March 2014 to October 2016.

\section{A- Patient selection}

Seven hundred and forty patients with hepatitis $C$ virus were selected if they had chronic HCV as proved by positive HCV RNA. The study population consists of three groups who were treated with different anti $\mathrm{HCV}$ regimens at different time intervals:

Group (1): included 240 patients (170 male - 70 female) who were treated with sofosbuvir $400 \mathrm{mg}$ orally once daily plus Peginterferon and weight-based ribavirin for 12 weeks with a mean age of (48.7 \pm 7.5 years $)$.

Group (2): included 250 patients (180 male - 70 female) who were treated with sofosbuvir and weight-based ribavirin for 24 weeks with a mean age of $(54.1 \pm$ seven years).

Group (3): included 250 patients (160 male - 90 female) who were treated with $400 \mathrm{mg}$ Sofosbuvir and $150 \mathrm{mg}$ of Simeprevir once daily for 12 weeks with the mean age of (53.4 \pm eight years).

\section{B- Clinical evaluation}

All the patients were subjected to entire history taking, clinical examination including clinical signs of portal hypertension as dilated abdominal veins, splenomegaly, the condition of the liver whether shrunken or enlarged in early cirrhosis, exclusion of features of liver cell failure as jaundice, ascites, lower limb edema, fetor hepaticus, flapping tremors, spider angiomata, palmar erythema. 


\section{C- Laboratory methods}

-Liver function and kidney function tests, prothrombin time, prothrombin concentration, the international normalized ratio (INR), complete blood count (CBC), HBsAg, TSH if interferon is used, ANA, serum alpha-fetoprotein.

We measured fasting blood sugar and glycosylated hemoglobin if the patient has diabetes. Also, we checked for a Pregnancy test for women of the childbearing period before ribavirin treatment. ECG, Fundus examination was done in patients above 50 years of age.

-Real-time Quantitative PCR was done at baseline (COBAS Ampliprep/Taqman HCV monitor, with detection limit 15 IU/ml; Roche Diagnostic Systems, Germany).

\section{D- Abdominal ultrasonography}

The patients were examined after 6 hours fast. Criteria of portal hypertension and cirrhosis were evaluated.

\section{E-Assessment of fibrosis stage by fibroscan.}

It was performed by fibroscan; the number of shots is 10 , success rate $\geq 60 \%$, interquartile range $\leq 25 \%$. Generally, liver stiffness $2.5-7 \mathrm{kPa}$ denotes (F0-1), 7-9.5 $\mathrm{kPa}(\mathrm{F} 2), 9.5-12.5 \mathrm{kPa}(\mathrm{F} 3),>12.5 \mathrm{kPa}$ denotes cirrhosis(15).

\section{Follow-up}

Patients were assessed by HCV RNA levels measured at baseline, the fourth week for assessment of adherence (optional), at the end-of-treatment, and the $12^{\text {th }}$-week post-treatment (SVR $12^{\text {th }}$ ). CBC, liver, and kidney function tests were done monthly during treatment.

\section{F- Statistical Analysis}

Data were analyzed using SPSS 20 for Windows (SPSS Inc., Chicago, IL, USA). When appropriate, continuous variables were summarized as mean \pm standard deviation and standard of error (SE). The Chi-square test was used for categorical variables as frequency and percentage. The analysis of variance was used appropriately. P-value was considered significant when $(\mathrm{P}<0.05)$. The Pearson correlation coefficient was used to detect variables correlated with SVR. The multivariate logistic regression analysis was performed to determine the independent variables associated with SVR. 


\section{Results}

The study was conducted on 740 patients, 510 males, and 230 females, with a mean age of $52.1 \pm 7.9$ years (35-74 years). BMI mean value was $28.1 \pm 3.1 \mathrm{~kg} / \mathrm{m}^{2}(22-39$ $\mathrm{kg} / \mathrm{m}^{2}$ ). Mean value of HCV RNA was $105.2 \pm 24.3 \times 10^{3} \mathrm{IU} / \mathrm{ml}$, Child Turcotte Pugh score (CTP) mean value 5.52 \pm 0.7 , FIB4 mean value $1.93 \pm 1.3(0.56-4.42)$,

Model of end-stage liver disease (MELD) mean value 8.42 \pm 2.2 .

The demographic features of the Studied Subgroups are shown in Table 1.

Table 1: Demographic Features of the Studied Subgroups

\begin{tabular}{lllll}
\hline & Triple therapy & Dual & Sim-Sof & P-value \\
\hline Age (years) & $48.7 \pm 7.5$ & $54.1 \pm 7$ & $53.4 \pm 8.5$ & 0.062 \\
Sex $(\mathbf{M} / \mathbf{F})$ & $(170-70)$ & $(180-70)$ & $(160-90)$ & 0.058 \\
BMI $\left(\mathbf{K g} / \mathbf{m}^{2}\right)$ & $20.7 \pm 3.6$ & $30.4 \pm 5.2$ & $37 \pm 2.4$ & 0.017
\end{tabular}

The mean value of the following variables showed a significant statistical difference among the studied groups; AST $(\mathrm{p}=0.03)$, HCV RNA by $(\mathrm{p}=0.000)$, platelet count $(\mathrm{p}=0.02)$ (Table 2).

Table 2: Baseline Laboratory Data of the Studied Subgroups

\begin{tabular}{lcccc}
\hline & Triple therapy & Dual & Sim-Sof & P-value \\
\hline ALT (IU/L) & $20.7 \pm 3.6$ & $30.4 \pm 5.2$ & $37 \pm 2.4$ & 0.151 \\
AST (IU/L) & $23.7 \pm 4$ & $35.8 \pm 6$ & $32 \pm 2.4$ & 0.03 \\
Albumin (g/dl) & $3.9 \pm 0.4$ & $3.5 \pm 0.4$ & $3.6 \pm 0.25$ & 0.063 \\
T.bilirubin (mg/dl) & $0.8 \pm 0.3$ & $1 \pm 0.3$ & $1 \pm 0.2$ & 0.1 \\
PT & $11.7 \pm 0.95$ & $12.8 \pm 1$ & $12.8 \pm 0.8$ & 0.28 \\
INR & $1.1 \pm 0.2$ & $1.2 \pm 0.2$ & $1 \pm 0.1$ & 0.12 \\
Creatinine (mg/dL) & $0.9 \pm 0.2$ & $1 \pm 0.2$ & $1 \pm 0.2$ & 0.195 \\
HCV RNA(KIU/mL) & $158.6 \pm 3.6$ & $108.9 \pm 6.2$ & $505 \pm 10.3$ & 0.000 \\
WBC (cells/ul) & $6.4 \pm 2.4$ & $6.13 \pm 1.4$ & $5.5 \pm 1.1$ & 0.1 \\
HB (g/dL) & $13.1 \pm 1.3$ & $11.9 \pm 1.6$ & $11.5 \pm 1$ & 0.164 \\
Platelets (/uL) & $183.2 \pm 51.4$ & $120.9 \pm 29$ & $222.7 \pm 61.1$ & 0.02 \\
\hline
\end{tabular}

CTP and FIB4 showed a highly significant statistical difference between the studied groups $(\mathrm{p}=0.001)$, higher in the dual therapy group $(6 \pm 0.7,3 \pm 0.3$ respectively). MELD mean value was significantly higher in the dual therapy group $(9.64 \pm 2.4$, $\mathrm{p}=0.002)$ (Table 3, Fig 1). 


\begin{tabular}{cccccc}
\hline \hline & $\begin{array}{c}\text { Triple } \\
\text { therapy }\end{array}$ & Dual & SIM-SOF & F & $\begin{array}{c}\text { P- } \\
\text { value(ANOV } \\
\text { A test) }\end{array}$ \\
\hline CTP & $5.2 \pm 0.5$ & $6 \pm 0.7$ & $5.4 \pm 0.5$ & 13.9 & 0.001 \\
FIB4 & $1.44 \pm 0.19$ & $3 \pm 0.3$ & $1.35 \pm 0.4$ & 18.5 & 0.000 \\
MELD & $7.5 \pm 1.8$ & $9.64 \pm 2.4$ & $8.04 \pm 1.9$ & 6.9 & 0.002 \\
\hline
\end{tabular}


African journal of gastroenterology and hepatology

Fig 1: FIB4, Child-Pugh score values among the studied groups.

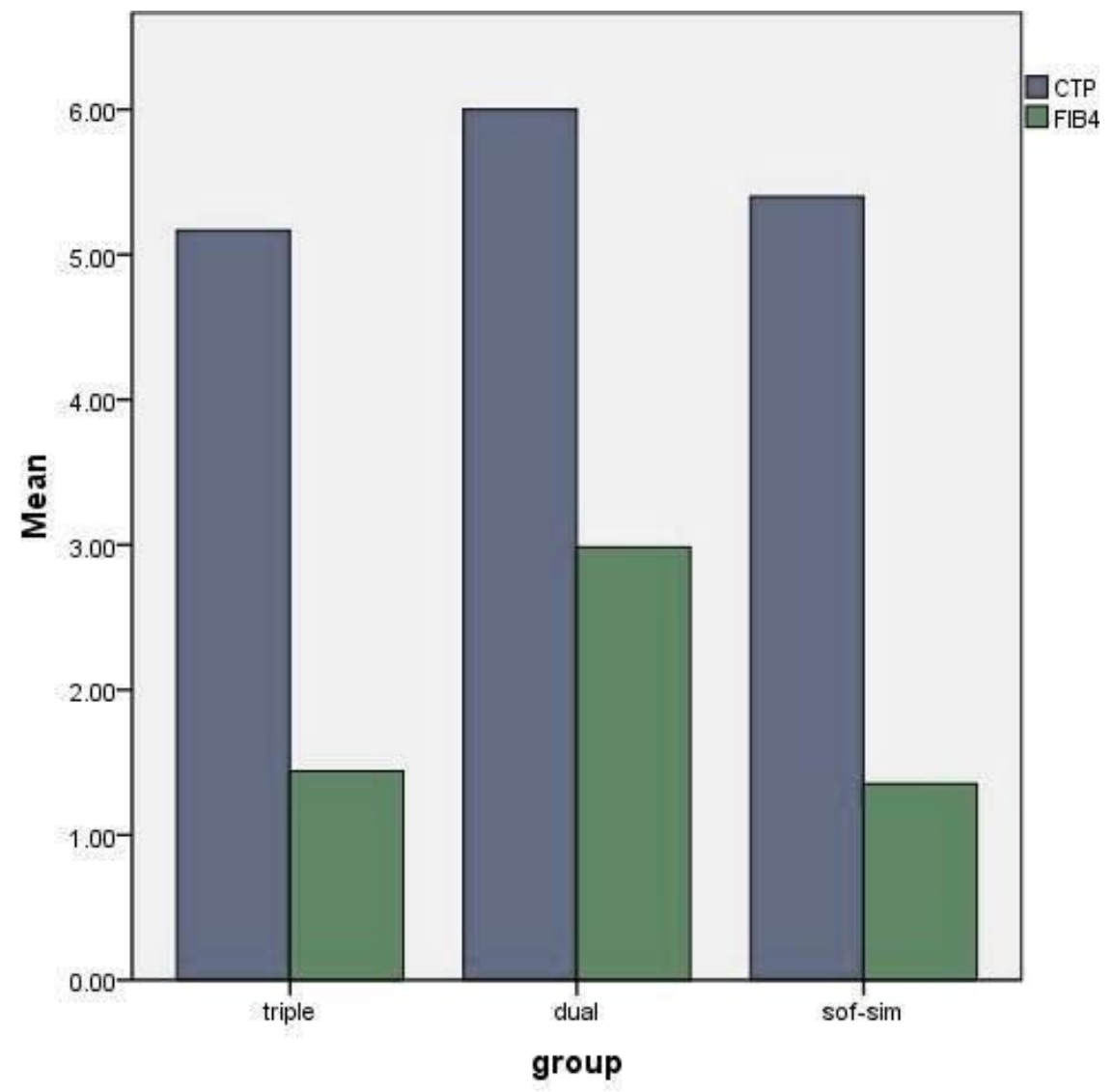

Fig1: FIB4, Child-Pugh score values among the studied groups.

Sustained virological response (SVR) occurred in $83 \%$ of the triple therapy group. In the dual therapy group, SVR occurred in $64 \%$ of patients. In the SimeprevirSofosbuvir group, SVR was achieved in $96 \%$ of patients with a statistically significant difference among the studied groups $(\mathrm{p}=0.015)$ (Table 4, Fig 2). 
African journal of gastroenterology and hepatology

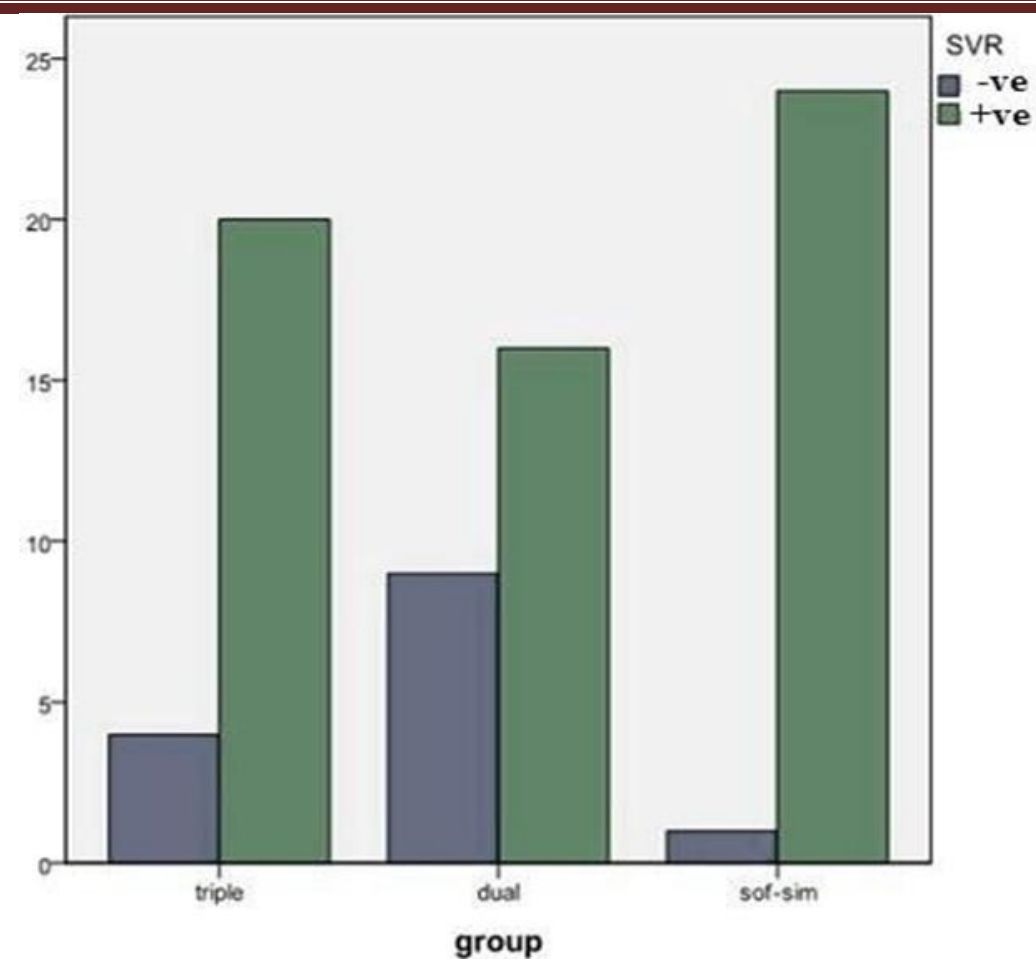

Fig 2: Prevalence of SVR among the studied groups. 
African journal of gastroenterology and hepatology

Table 4: Incidence of sustained virological response (SVR) among the studied subgroups.

\begin{tabular}{ccccc}
\hline & Triple therapy & Dual & SIM-SOF & P-value \\
\hline SVR & $200(83.3 \%)$ & $160(64 \%)$ & $240(96 \%)$ & \\
No SVR & $\mathbf{4 0}(\mathbf{1 6 . 7 \% )}$ & $\mathbf{9 0}(\mathbf{3 6 \%})$ & $\mathbf{1 0}(\mathbf{4 \%})$ & $\mathbf{P}=\mathbf{0 . 0 1 5}$ \\
\hline
\end{tabular}

The Pearson correlation coefficient was done to detect variables closely correlated with SVR (Table 5). Treating patients with Simeprevir and sofosbuvir has a likelihood ratio of 9.1 of achieving SVR.

Table 5: Spearman rank correlation to detect variables closely correlated with SVR.

\section{Variables Type of treatment Platelet count Creatinine CTP}

$\begin{array}{rrrrr}\mathrm{R} & 0.345 & 0.264 & 0.312 & 0.293 \\ \mathrm{P} & 0.000 & 0.023 & 0.007 & 0.011\end{array}$

Multivariate logistic regression analysis was performed to detect the variables independently associated with SVR. Simeprevir and sofosbuvir were associated with higher rates of SVR with an odds ratio of 12.5 . Serum creatinine negatively correlates with SVR; the higher the value, the less the likelihood of achieving SVR with an odds ratio of 3.1. The MELD score showed a negative correlation with SVR; the lower the score, the more the possibility of the SVR with an odds ratio of 1.5 (Table 6).

Table 6: Multivariate logistic regression analysis to determine the independent variables associated with SVR.

\begin{tabular}{llll}
\hline & Beta coefficient & Odds ratio & $\mathrm{P}$ \\
\hline Type of treatment & 4.8 & 12.5 & 0.02 \\
Serum creatinine & -28.8 & & \\
MELD & -2.6 & 3.1 & 0.02 \\
\end{tabular}

While observing the side effects of therapy among the studied subgroups, in the 1st group, which was treated with triple therapy, ten patients had no adverse effects (4.2\%), 120 patients had fatigue (50\%). Seventy patients had a headache (29.2\%), 40 patients had nausea $(16.7 \%), 130$ patients developed normocytic normochromic 
anemia (54.2\%), which necessitated stopping the therapy temporarily in 30 patients for $4.3 \pm 2.9$ days, no one experienced arthritic manifestations as joint pain, pruritus or rash.

In the second group, which was treated with sofosbuvir and ribavirin; 110 patients had no adverse effects (44\%), 80 patients had fatigue (32\%), 40 patients had a headache (16\%), 20 patients had nausea (8\%), 110 patients developed normocytic normochromic anemia (44\%) which needed to stop the therapy temporarily in 13 patients for 3.9 \pm 2.6 days, no one experienced arthritic manifestations as joint pain, pruritis or rash.

In the third group, which was treated with sofosbuvir and simeprevir; 110 patients had no adverse effects (44\%), 50 patients had fatigue (20\%), 20 patients had a headache (8\%), 30 patients had nausea (12\%), ten patients had joint pain (4\%), 20 patients had joint pain (8\%), ten patients had a rash $(4 \%)$, and five patients $(2 \%)$ developed mild normocytic normochromic anemia (Table7).

Table 7: Frequency of the side effects among the studied subgroups

\begin{tabular}{|c|c|c|c|c|c|c|c|c|c|c|}
\hline & & & \multirow[b]{2}{*}{ No $S / E$} & \multicolumn{7}{|c|}{ Side effects } \\
\hline & & & & Fatigue & Headache & Anemia & Nausea & Joint pain & pruritis & Rash \\
\hline \multirow[t]{6}{*}{ Group } & Triple & Count & 10 & 120 & 70 & 130 & 40 & 0 & 0 & 0 \\
\hline & & $\%$ & $4.2 \%$ & $50.0 \%$ & $29.2 \%$ & $54.2 \%$ & $16.7 \%$ & $0.0 \%$ & $0.0 \%$ & $0.0 \%$ \\
\hline & Dual & Count & 110 & 80 & 40 & 110 & 20 & 0 & 0 & 0 \\
\hline & & $\%$ & $44.0 \%$ & $32.0 \%$ & $16.0 \%$ & $44 \%$ & $8.0 \%$ & $0.0 \%$ & $0.0 \%$ & $0.0 \%$ \\
\hline & SOF-SIM & Count & 110 & 50 & 20 & 5 & 30 & 10 & 20 & 10 \\
\hline & & $\%$ & $44.0 \%$ & $20.0 \%$ & $8.0 \%$ & $2 \%$ & $12.0 \%$ & $4.0 \%$ & $8.0 \%$ & $4.0 \%$ \\
\hline \multirow[t]{2}{*}{ Total } & & Count & 230 & 250 & 130 & 245 & 90 & 10 & 20 & 10 \\
\hline & & $\%$ & $31.1 \%$ & $33.8 \%$ & $17.6 \%$ & $33.1 \%$ & $12.2 \%$ & $1.4 \%$ & $2.7 \%$ & $1.4 \%$ \\
\hline
\end{tabular}

\section{Discussion}

The Sustained virological response is defined as undetectable HCV RNA in the serum 24 weeks after the end of treatment; it is associated with improved outcomes in the form of a reduction in the rate of hepatocellular carcinoma (HCC), liver decompensation, and enhanced survival (16).

Until recently, the standard of care for genotype $4 \mathrm{HCV}$ had been pegylated interferon with ribavirin for 24 to 48 weeks, depending on virological response. Treatment-naive patients who received this regimen had SVR rates of $43 \%$ to $60 \%$ (17). 
Direct-acting antiviral agents have recently been approved to treat genotype $4 \mathrm{HCV}$. They are associated with improved rates of SVR in treatment-naive and treatmentexperienced patients with genotype $4 \mathrm{HCV}$; however, a small number of patients were studied, and data concerning efficacy and safety are lacking(18). The efficacy and safety of sofosbuvir in patients with different $\mathrm{HCV}$ genotypes and various combinations of drugs were tested in numerous clinical trials(19).

In our retrospective study analyzing the efficacy of sofosbuvir-based therapy for the hepatitis $\mathrm{C}$ virus genotype, four patients in Egypt, conducted on 740 patients, divided into three groups that declared the following results. The first group of naïve patients included 240 patients treated with sofosbuvir $400 \mathrm{mg}$ orally plus peginterferon alfa-2a and weight-based ribavirin for 12 weeks. Two hundred patients had achieved SVR (83\%), $40(17 \%)$ patients had a recurrence, 15 after therapy, 25 patients after three months.

The results of SVR in the 1st group are approximately in agreement with the results of the NEUTRINO study, which was conducted on naïve patients with HCV infection. A 12-week regimen of sofosbuvir plus peginterferon alfa-2a and ribavirin in 327 patients with HCV genotype 1, 4, 5, or 6. The primary endpoint was SVR at 12 weeks. SVR was achieved in $90 \%$ of patients(20).

In the second group of patients, which included 250 peginterferon experienced patients who took sofosbuvir and weight-based ribavirin for 24 weeks; 160 patients achieved SVR (64\%), 90 (36\%) patients had a recurrence, 42 of them at the end of treatment, 48 patients after three months. The results of SVR in the 2nd group are approximately in agreement with the results of the phase 2 trial in patients with chronic HCV infection (either genotype 2 or 3), which showed that treatment with sofosbuvir plus ribavirin resulted in SVR in 100\% (10 of 10) of previously untreated patients and $68 \%$ (17 of 25) of previously treated patient(21)s (22).

A study enrolled treatment-naïve or treatment-experienced patients with genotype 4 HCV infection $(n=103)$ who were randomly assigned to receive either 12 or 24 weeks of sofosbuvir $400 \mathrm{mg}$ and ribavirin 1000-1200 mg daily. Randomization was stratified by prior treatment experience and the presence or absence of cirrhosis. The primary endpoint was the percentage of patients SVR12th.SVR12 rates were 90\% (46/51) with 24 weeks and $77 \%$ (40/52) with 12 weeks of sofosbuvir and ribavirin therapy. Patients 
with cirrhosis at baseline had lower rates of SVR12 (63\% 12 weeks, $78 \% 24$ weeks) than those without cirrhosis (80\% 12 weeks, 93\% 24 weeks)(23) [23].

In the third group that included 250 patients who were treated with $400 \mathrm{mg}$ sofosbuvir and $150 \mathrm{mg}$ of simeprevir once daily for 12 weeks; 240 patients achieved SVR (96\%) , ten patients did not continue treatment due to the side effects.

The results of SVR in the 3rd group were approximately in agreement with the results of the OSIRIS trial, which assessed genotype four infected patients $(n=63)$ both treatment naïve and experienced, with and without liver cirrhosis, who were treated with $150 \mathrm{mg}$ of simeprevir in combination with $400 \mathrm{mg}$ sofosbuvir once daily. Patients without liver cirrhosis were randomized to receive either 8 or 12 weeks of treatment, while patients with cirrhosis were assigned to receive 12 weeks. In patients $(n=43)$ treated for 12 weeks, SVR was $100 \%$, and $75 \%$ of patients $(n=20)$ treated for 8 weeks 
There is a statistically significant difference in SVR incidence among the studied subgroups $(\mathrm{p}=0.015)$. Hematological abnormalities did not occur except for normocytic anemia in 245 (33\%) patients, which was noted in patients receiving ribavirin and forced us to stop treatment temporarily in $43(5.8 \%)$ patients. The low incidence of adverse events with the relatively short duration of treatment as compared to IFN-based therapy might improve treatment adherence and completion.

Combining DAAs for 12-24 weeks had established the potential of IFN-free regimens for both treatment-naive patients, and interferon experienced patients with $\mathrm{HCV}$ genotype 4 with higher efficacy and sustained virological rates. In conclusion, Sofosbuvir-based therapy has better results for treating hepatitis $\mathrm{C}$ virus genotype four and has lesser complications than the previous antiviral combination therapy with interferon and ribavirin.

\section{Author contributions}

Waleed Abdul Fattah provided study design, clinical evaluation, and supervision of the work. Amr Hanafy provided the Study design, clinical evaluation, writing, statistical analysis. Mohammed Abdelsattar aided in the collection of clinical and laboratory data. All authors approved the final version of the manuscript.

\section{Acknowledgment}

Special thanks to clinical pathologists and diagnostic radiology physicians at Zagazig University, Fakous, and Alahrar hospitals, who were kind and provided us with great help in performing laboratory and diagnostic investigations with high efficiency.

\section{Compliance with Ethical Standards:}

- Disclosure of potential conflicts of interest: No conflict of interest.

- The research is self-funded.

-All procedures were performed by the ethical standards of the Zagazig universityfaculty of the medical research committee and with the Helsinki Declaration and its later amendments. Informed consent was obtained from each patient who participated in

the

study. 


\section{Footnotes}

Citation of this article: Ismail W, Hanafy A, Abdelsattar M. The outcome of the sofosbuvir Based Therapy in treating Hepatitis C Virus Genotype 4 in Egyptian patients. African journal of gastroenterology and hepatology [Internet]. The Scientific Society of Kafr el-sheik Doctors; 2019 Feb 5;2(1):1-18. Available from: https://dx.doi.org/10.52378/alkj/2738

Peer- Reviewers: Hanan Soliman, Anas Kassem, Mohamed Basuony, Talaat Fathy. Executive- Editors: Emad Abdellatif Emam, E- Editor: Salem Y Mohamed, Hany Elsadek.

Copyright (C. This open-access article is distributed under the Creative Commons Attribution License (CC BY). The use, distribution, or reproduction in other forums is permitted, provided the original author(s) and the copyright owner(s) are credited. The original publication in this journal is cited by accepted academic practice. No use, distribution, or reproduction is permitted, which does not comply with these terms. Disclaimer: All claims expressed in this article are solely those of the authors and do not necessarily represent their affiliated organizations or those of the publisher, the editors, and the reviewers. Any product that may be evaluated in this article or claim that its manufacturer may make is not guaranteed or endorsed by the publisher. 


\section{References:}

1. Kandeel A, Genedy M, El-Refai S, Funk AL, Fontanet A, Talaat M. The prevalence of hepatitis $C$ virus infection in Egypt 2015: implications for future policy on prevention and treatment. Liver International. 2017;37(1):45-53.

2. Tong MJ, El-Farra NS, Reikes AR, Co RL. Clinical outcomes after transfusionassociated hepatitis C. New England Journal of Medicine. 1995;332(22):1463-6.

3. Schuppan D, Afdhal NH. Liver cirrhosis. The Lancet. 2008;371(9615):838-51. 4. Swain MG, Lai MY, Shiffman ML, Cooksley WGE, Zeuzem S, Dieterich DT, et al. A sustained virologic response is durable in patients with chronic hepatitis $C$ treated with peginterferon alfa-2a and ribavirin. Gastroenterology. 2010;139(5):1593-601.

5. Torriani FJ, Rodriguez-Torres M, Rockstroh JK, Lissen E, Gonzalez-García J, Lazzarin A, et al. Peginterferon Alfa-2a plus ribavirin for chronic hepatitis $\mathrm{C}$ virus infection in HIVinfected patients. New England Journal of Medicine. 2004;351(5):438-50.

6. Feld JJ, Hoofnagle JH. Mechanism of action of interferon and ribavirin in treatment of hepatitis C. Nature. 2005;436(7053):967.

7. Sidwell RW, Huffman JH, GP Khare L, Allen B, JT Witkowski R, Robins K. Broadspectrum antiviral activity of virazole: 1-f8-D-ribofuranosyl-1, 2, 4-triazole-3-carboxamide. Science. 1972;177(4050):705-6.

8. McHutchison JG, Gordon SC, Schiff ER, Shiffman ML, Lee WM, Rustgi VK, et al. Interferon alfa-2b alone or in combination with ribavirin as initial treatment for chronic hepatitis C. New England Journal of Medicine. 1998;339(21):1485-92.

9. Feeney ER, Chung RT. Antiviral treatment of hepatitis C. Bmj. 2014;349:g3308.

10. Aghemo A, De Francesco R. New horizons in hepatitis $C$ antiviral therapy with direct-acting antivirals. Hepatology (Baltimore, Md). 2013;58(1):428-38.

11. Keating GM, Vaidya A. Sofosbuvir: first global approval. Drugs. 2014;74(2):273-82.

12. Cholongitas E, Papatheodoridis GV. Sofosbuvir: a novel oral agent for chronic hepatitis C. Annals of Gastroenterology: Quarterly Publication of the Hellenic Society of Gastroenterology. 2014;27(4):331.

13. Izquierdo L, Helle F, François C, Castelain S, Duverlie G, Brochot E. Simeprevir for the treatment of hepatitis $C$ virus infection. Pharmacogenomics and personalized medicine. 2014;7:241.

14. Castera L, Forns $X$, Alberti A. Non-invasive evaluation of liver fibrosis using transient elastography. Journal of hepatology. 2008;48(5):835-47. Epub 2008/03/13.

15. Sarrazin C, Zeuzem S. Resistance to direct antiviral agents in patients with hepatitis $C$ virus infection. (1528-0012 (Electronic)).

16. Gentile I, Buonomo AR, Zappulo E, Borgia G. Interferon-free therapies for chronic hepatitis $C$ : toward a hepatitis $C$ virus-free world? Expert review of anti-infective therapy. 2014;12(7):763-73.

17. Nguyen $\mathrm{NH}$, McCormack SA, Vutien $\mathrm{P}$, Yee BE, Devaki $\mathrm{P}$, Jencks $\mathrm{D}$, et al. Metaanalysis: superior treatment response in Asian patients with hepatitis $C$ virus genotype 6 versus genotype 1 with pegylated interferon and ribavirin. Intervirology. 2015;58(1):27-34 .

18. Kanda T, Nakamoto S, Nakamura M, Jiang X, Miyamura T, Wu S, et al. Direct-acting antiviral agents for the treatment of chronic hepatitis $C$ virus infection. Journal of clinical and translational hepatology. 2014;2(1):1.

19. Lawitz E, Mangia A, Wyles D, Rodriguez-Torres M, Hassanein T, Gordon SC, et al. Sofosbuvir for previously untreated chronic hepatitis $\mathrm{C}$ infection. New England Journal of Medicine. 2013;368(20):1878-87.

20. Gane EJ, Stedman CA, Hyland RH, Sorensen RD, Symonds WT, Hindes R, et al. once Daily Sofosbuvir (gs-7977) Plus Ribavirin in Patients with Hcv Genotypes 1, 2, and 3: The Electron Trial: 229. Hepatology (Baltimore, Md). 2012;56:306A-7A. 
21. Gane EJ, Stedman CA, Hyland RH, Ding X, Svarovskaia E, Symonds WT, et al. Nucleotide polymerase inhibitor sofosbuvir plus ribavirin for hepatitis $C$. New England Journal of Medicine. 2013;368(1):34-44.

22. Doss W, Shiha G, Hassany M, Soliman R, Fouad R, Khairy M, et al. Sofosbuvir plus ribavirin for treating Egyptian patients with hepatitis $C$ genotype 4. Journal of hepatology. 2015;63(3):581-5.

23. Buti $M$, Calleja J, Lens S, Diago M, Ortega E, Crespo J, et al. Simeprevir in combination with sofosbuvir in treatment-naïve and-experienced patients with hepatitis $C$ virus genotype 4 infection: a Phase III, open-label, single-arm study (PLUTO). Alimentary pharmacology \& therapeutics. 2017;45(3):468-75.

24. El Kassas M, Elbaz T, Elsharkawy A, Omar H, Esmat G. HCV in Egypt, prevention, treatment and key barriers to elimination. Expert review of anti-infective therapy. 2018;16(4):345-50. 